\title{
AS TEORIAS INSTITUCIONAIS E A FORMAÇÃO DO ESTADO BRASILEIRO
}

http://dx.doi.org/10.21527/2176-6622.2018.50.64-74

Recebido em: 21/9/2017

Aceito em: 13/9/2018

Ramá Lucas Andrade

Professor-adjunto no Departamento de Economia da Universidade Regional do Cariri - Urca, com pesquisa nas áreas de Desenvolvimento Regional, Finanças e Direito Econômico. ramalucas@hotmail.com

João Luis do Nascimento Mota

Professor-adjunto no Departamento de Economia da Universidade Regional do Cariri - Urca, com pesquisa nas áreas de Teoria da Organizações e Direito Econômico. motajoaoluis@yahoo.com.br

\section{RESUMO}

A Nova Economia Institucional vai influenciar o pensamento político e social, a partir do pós-guerra e se fortalecer com a globalização, transformando-se em instrumento teórico para diversas outras ciências, como é o caso do Direito. Neste contexto, o presente artigo buscará compreender como as instituições e as teorias institucionais influenciaram a formação do Estado brasileiro. Para tal incursão é feito um estudo sobre as teorias institucionais e, em seguida, estuda-se a influência das instituições e do Institucionalismo para a formação do Estado brasileiro. Este artigo, do ponto de vista da abordagem do problema, foi tratado de forma qualitativa; em relação aos objetivos foi utilizada a pesquisa descritiva e do ponto de vista dos procedimentos técnicos foi realizada mediante um estudo bibliográfico. No Brasil, a estrutura social está assentada em valores da racionalidade econômica. A autonomia da vontade privada e os pressupostos de liberdade e igualdade, anunciados pelo liberalismo e posteriormente pelo neoliberalismo, conduzem as relações sociais.

Palavras-chave: Teorias institucionais. Estado brasileiro. Racionalidade econômica. Estado democrático. Liberalismo.

\section{INSTITUTIONAL THEORY AND TRAINING OF THE BRAZILIAN STATE}

\section{ABSTRACT}

The New Institutional Economy will influence political and social thinking from the post-war period and strengthen itself with globalization, becoming a theoretical instrument for several other sciences, such as Law. In this sense, this article will seek to understand how institutions and institutional theories influenced the formation of the Brazilian State. For such an incursion is made a study on the institutional theories and then studies the influence of institutions and Institutionalism for the formation of the Brazilian State. This article, from the point of view of the problem approach, was treated in a qualitative way, in relation to the objectives was used descriptive research, from the point of view of technical procedures was carried out through a bibliographic study. In Brazil, the social structure is based on values of economic rationality. The autonomy of the private will and the presuppositions of freedom and equality, announced by liberalism and later by neoliberalism, drive social relations.

Keywords: Institutional theories. Brazilian State. Economic rationality. Democratic State. Liberalism.

\section{SUMÁRIO}

1 Introdução. 2 As Teorias Institucionais. 3 As Instituições e a Formação do Estado Brasileiro. 4 Conclusão. 5 Referências. 


\section{INTRODUÇÃO}

O entendimento do termo "instituições" passa necessariamente por uma análise metodológica, mais profunda que uma questão de semântica ou conceituação. Deve-se aproximar muito mais da semiótica e da representação do termo, em todas as suas manifestações, para uma organização das estruturas e das relações sociais.

Este esforço deve ser delineado por uma imersão nos pressupostos da Teoria Institucional, desenvolvida pelas Ciências Sociais para explicar a sociedade por meio de suas instituições.

Existem diversas concepções teóricas que nem sempre convergem entre as suas abordagens institucionalistas. Entre as divergências encontra-se a própria definição de instituição, que pode significar tanto normas de comportamento quanto institucionais ou padrão de organização da firma ou direito de propriedade.

Entre as diversas abordagens utilizadas, este artigo tem como marco temporal pesquisas empíricas realizadas no campo das organizações, sob os enfoques estrutural e comportamental.

Os chamados velhos institucionalistas, como Veblen, Commons e Mitchel, focaram sua análise na chamada economia evolucionária. ${ }^{1}$ Esta abordagem centra-se em três indicativos: a inadequação da teoria neoclássica ${ }^{2}$ em tratar as inovações, supondo-as dadas, e, portanto, desconsiderando as condições de sua efetivação; a preocupação, não com o equilíbrio estável, mas em como se dá a mudança e o consequente crescimento; e a ênfase no processo de evolução econômica e transformação tecnológica (CONCEIÇÃO, 2000).

Deve-se destacar que foram as ideias de Veblen, em um artigo chamado "Why is economics not an evolutionary science?", escrito em 1898, em que o autor estabelece como alternativa a construção de uma teoria econômica evolucionária, na qual instintos, hábitos e instituições exercem na evolução econômica papel análogo aos genes na Biologia.

Tais estudos influenciaram outros pesquisadores, como Philip Selznick, na década de 50 do século 20, ao introduzir as bases de um modelo institucional e interpretar as organizações como uma expressão estrutural da ação racional que, ao longo do tempo, são sujeitas às pressões do ambiente social e transformam-se em sistemas orgânicos. Segundo Vinicius C. de Sá (2011), esta evolução, que Selznick designa como processo de institucionalização, pode ser sintetizada num aspecto: os valores substituem os fatores técnicos na determinação das tarefas organizativas.

O Institucionalismo de Philip Selznick, também conhecido como velho Institucionalismo, tem suas bases de oposição às teorias neoclássicas, na perspectiva econômica.

A Sociologia, por outro lado, lida com as relações, os processos e as estruturas sociais. Um tema particularmente importante da reflexão sociológica é a interação social, momento primordial na gênese e reiteração do social. Todo fato social caracteriza-se por ser um nexo de relações sociais (IANNI, 1996, p. 27).

De maneira geral, estas concepções têm nas instituições sua base de análise, partem da discussão de suas diferenças com o neoclassicismo e suas afinidades com o evolucionismo; buscam, ainda, identificar analiticamente pontos de concordância, que permitam a constituição de uma possível teoria institucionalista. Assim, sua generalidade está em indicar como desenvolver análises específicas e variadas em relação a um fenômeno específico.

A Escola do Institucionalismo da Escolha Racional vai influenciar toda uma corrente de pensamento, o que provoca o surgimento da Nova Economia Institucional (NEI). Esta preocupa-se, fundamentalmente, com aspectos microeconômicos, com ênfase na teoria da firma, que mescla história econômica, economia dos direitos de propriedade, sistemas comparativos, economia do trabalho e organização industrial. As figuras mais expressivas desta escola são Ronald Coase, Oliver Williamson e Douglass North, que se ocupam de estudos na área de organização e operação das empresas, formação de mercados, a divisão de atividades entre corpo-

\footnotetext{
${ }^{1}$ Esta abordagem traz como fundamento uma aproximação entre a biologia evolucionária e economia institucional. Para maior aprofundamento sobre o assunto ver: HODGSON, Geoffrey M. The Approach of Institutional Economics. Journal of Economic Literature, v. $36,1998$.

${ }^{2}$ Economia Neoclássica designa diversas correntes do pensamento econômico, também conhecido como Marginalismo, que buscou integrar a teoria da utilidade do valor com a teoria do custo de produção da Escola Clássica, bem como explicar os preços dos bens e dos fatores, e a alocação dos recursos com o auxílio da análise marginal. Para maiores detalhes ver: VASCONCELLOS, Marco Antonio Sandoval de. Manual de economia. 2. ed. 4a tiragem. São Paulo: Saraiva, 1996.
} 
rações e mercados e a formação de sistemas de mercado e instituições que formam esses sistemas. Centram sua análise nos custos de transação e, no caso de North, em estudos mais recentes, no papel do poder e da ideologia na evolução institucional e sistêmica.

A Nova Economia Institucional, por sua vez, vai influenciar o pensamento político e social, a partir do pós-guerra, e se fortalecer com a globalização, transformando-se em instrumento teórico para diversas outras ciências, como é o caso do Direito.

Tais influências conduzem a formulações teóricas e práticas de construção da sociedade, que podem ser assim elencadas: i) liberalismo: quem deve ordenar as relações econômicas e sociais é o mercado; Estado mínimo; liberdade para o capital internacional; ii) democracia representativa: fortalecimento das instituições e um Estado que não deve ser um resumo do pensamento popular, mas um pensamento refletido e separado do pensamento coletivo, incumbido de entender e decidir da forma mais benéfica a todos; iii) estrutura social: dividida em estamentos, em que alguns, eleitos, estão qualificados para a condução da sociedade e a busca do bem comum.

No momento em que se busca compreender as atuais democracias com suas estruturas e influências, deve-se procurar entender o papel das instituições e da participação popular para a construção do Estado Democrático de Direito e a sua influência para a consecução da Justiça.

Entre as inúmeras escolas, e suas vertentes nas diversas ciências, que buscam resolver o problema da melhor democracia, este trabalho buscou delimitar o tema dentro de uma possibilidade que analisasse a democracia representativa, ou na sua versão liberal, a qual tem o mercado como balizador das atividades legislativas, jurídicas e políticas, ou por meio do intervencionismo estatal, como é o caso do Estado de bem-estar social.

No contexto deste debate e das atuais democracias, anteriormente exposto, traz-se à baila o Estado brasileiro, que tem as bases da ordem econômica-política-jurídica-social do Estado estabelecidas constitucionalmente - Constituição Federal de 1988 - e que indicam sua opção pelo sistema liberal representativo.

Estes problemas, enfrentados pelo Estado brasileiro, sofrem influência direta das questões políticas e econômicas em todo o mundo. Este é o resultado, por um lado, das chamadas economias abertas (caso do Brasil), nas quais as suas estruturas de produção e distribuição da riqueza estão diretamente relacionadas ao mercado global, sendo influenciado e influenciando as estratégias sociopolíticas; por outro lado, as consequências de um mundo mais globalizado, onde não existem limitações de espaço e idiomas, provocando uma difusão planetária de informações, que rompem e criam novos paradigmas, estimulando um novo modo de ser, de pensar e de agir, desse novo cidadão do mundo.

Não obstante a complexidade dos Estados modernos e de suas interconexões, faz-se necessário um esforço para tornar a pesquisa científica passível de observações. Abstrações e digressões devem conduzir aos chamados cortes teóricos, espaciais e temporais, com o propósito de inferências na realidade e observância dos resultados.

Nesse sentido, este artigo buscará compreender como as instituições e as teorias institucionais influenciaram a formação do Estado brasileiro. Para tal incursão é feito um estudo sobre as teorias institucionais e, em seguida, estuda a influência das instituições e do Institucionalismo para a formação do Estado brasileiro. Este artigo, do ponto de vista da abordagem do problema, foi tratado de forma qualitativa, pois considera que existe uma relação entre o mundo e o sujeito traduzida em representações não numéricas. Em relação aos objetivos foi utilizada a pesquisa descritiva, uma vez que buscou descrever as características de um fenômeno. Do ponto de vista dos procedimentos técnicos foi realizada mediante um estudo bibliográfico, dado que procura explicar um problema a partir de referências teóricas publicadas em documentos (GIL, 2007).

\section{AS TEORIAS INSTITUCIONAIS}

É possível perceber que estes estudos sobre as instituições irão sofrer divergências, em anos seguintes, apropriados por diversas ciências e servindo de base para uma gama de concepções teóricas. Entre as ciências podem ser destacados estudos nas áreas da Economia, da Sociologia e da Ciência Política.

$O$ enfoque institucional desenvolveu-se em três vertentes: 
A orientação econômica insere o processo econômico no marco da construção social, entre outras forças como a história e os aspectos culturais. Eleva os elementos empresas, mercados e relações contratuais a uma estrutura organizacional. Com Veblen, em oposição ao paradigma dominante, homo economicus, ${ }^{3}$ dizia que os costumes e as convenções determinavam o comportamento econômico e que o indivíduo era influenciado pelas instituições. Com Commons e Mitchel rebate a ideia da teoria econômica com eficiência estática e com equilíbrio de mercado, trazendo o Institucionalismo como instrumento de estudo de processos dinâmicos e evolução cultural. Em estudos mais recentes, como os de Williamson e Coase, as transações são a principal unidade de análise e são ademais responsáveis pela definição dos mercados, das hierarquias e das formas híbridas das organizações (CARVALHO, 1999).

A orientação política inicialmente manteve uma estreita relação com o Direito Constitucional e a Filosofia moral concedendo, segundo Scott (1995), especial atenção aos aspectos legais e à ordenação administrativa das estruturas de governo. Com este ocorreu um deslocamento do foco teórico das estruturas e das normas para os comportamentos dos indivíduos. Segundo os institucionalistas, a modernidade na sociedade burocrática é responsável pela transformação paulatina das instituições sociais, políticas e econômicas. Dessa forma as instituições cresceram, adquiriram uma considerável parcela de poder, tornaram-se mais complexas e eficazes. Para estes teóricos é o protagonismo das instituições que está na origem do interesse da ciência política. Os trabalhos recentes concentram-se em questões como a autonomia relativa das instituições políticas em relação à sociedade; a complexidade dos sistemas políticos existentes e o papel central exercido pela representação e o simbolismo no universo político. Tais pesquisas são foco de análise de processos de tomadas de decisão por instituições domésticas, assim como resultados para relações internacionais (CARVALHO, 1999).

Já na orientação sociológica aparece a influência de Émile Durkheim, com as suas contribuições iniciais sobre o caráter variável das bases da ordem social, destacando o papel exercido pelos sistemas simbólicos, os sistemas de conhecimento, de crença e a autoridade moral, identificados como instituições sociais, produtos da interação humana. Weber, em seus estudos sociológicos sobre o nascimento do capitalismo, aprofundou-se tanto na compreensão da influência das normas culturais como na construção e no caráter histórico das estruturas econômicas e sociais. Com Berger e Luckmann centra-se na investigação da natureza e origem da ordem social, que serviu de base para o chamado novo Institucionalismo nas organizações. Mais recentemente, Meyer, Rowan e Zucker destacaram o papel das normas culturais e de elementos institucionais como normas profissionais e organismos do Estado no processo de institucionalização (CARVALHO, 1999).

As ideias aqui expostas trazem uma sugestão de aglutinação de pensamentos, contudo, apesar de tornar mais didática sua compreensão, não se deve olvidar as divergências entre as vertentes anteriormente expostas. Também havia divergências entre os teóricos que conviveram no mesmo período, e entre as escolas de períodos diferentes. Assim, apesar de algumas bases conceituais estarem em escolas diferentes, pode-se destacar oposições entre o pensamento dos chamados velhos institucionalistas e dos novos institucionalistas. E entre estes últimos, várias concepções: como o Institucionalismo histórico, o Institucionalismo da escolha racional e o Institucionalismo sociológico.

O chamado Neoinstitucinalismo, nasce por volta das décadas de 80 e 90, a partir de pensadores que se posicionam opostos aos institucionalistas, ou ao Velho Institucionalismo, que tinham sua estrutura no funcionalismo, behaviorismo, ${ }^{4}$ e marxismo, e baseavam seus estudos na crítica às Escolas Clássica e Neoclássica. Já os Neoinstitucionalistas buscaram uma revitalização e uma expansão dos elementos institucionalistas encontrados em economia clássica e neoclássica.

Enquanto os velhos institucionalistas são considerados descritivistas, antiformalistas, holistas, behavioristas e coletivistas, além de rejeitarem os critérios individualistas de bem-estar e serem mais intervencionistas, mostrando-se a favor de um maior envolvimento do governo na correção de falhas institucionais; os

\footnotetext{
${ }^{3}$ Construção fictícia, desenvolvida por volta do século 19 , de um homem sem outras dimensões, como a moral, ética, religiosa, política e outras. Alguém que apenas produz e consome.

${ }^{4}$ Do inglês Behavior - comportamento - Teoria psicológica enunciada pelo norte-americano John B. Warson em decorrência de estudos experimentais sobre o comportamento reflexo efetuados por I. Pavlov. Cf. CABRAL, Álvaro; NICK, Eva. Dicionário técnico de psicologia. 14. ed. São Paulo: Cultrix, 2006. p. 41.
} 
neoinstitucionalistas são considerados mais formalistas (especialmente no que se refere às teorias neoclássicas e à teoria dos jogos), individualistas, reducionistas, orientados em direção à escolha racional e a modelos estritamente econômicos, e geralmente anti-intervencionistas.

Os chamados neoinstitucionalistas não desenvolveram uma corrente de pensamento unificada, e seus métodos de análise tiveram como vertentes:

O Institucionalismo Histórico, que se desenvolveu como reação à análise política em termos de grupos e contra o estruturo-funcionalismo. Preocupam-se com a organização institucional da comunidade política e as estruturas econômicas entram em conflito, de tal modo que determinados interesses são privilegiados em detrimento de outros. Consideram que a comunidade política ou a economia política é o principal fator a estruturar o comportamento coletivo. Privilegiam a estrutura (estruturalismo) das instituições políticas ao funcionalismo das teorias anteriores. Além de mudança no papel do Estado, que não é mais neutro, estudam também o comportamento da organização do capital e do trabalho, incluindo relações entre legisladores, os interesses organizados, o eleitorado e o poder Judiciário.

Tais pesquisas serviram de base para estudos comparados, entre países, estendendo suas análises para os movimentos dos trabalhadores, as organizações patronais e os sistemas financeiros de diversos países. Esta escola tem como características: 19) esses teóricos tendem a conceituar a relação entre as instituições e o comportamento individual em termos muito gerais; 2 ㅇ) enfatizam as assimetrias de poder associadas ao funcionamento e ao desenvolvimento das instituições; 3 ㅇ) tendem a formar uma concepção do desenvolvimento institucional que privilegia as trajetórias, as situações críticas e as consequências imprevistas; e 4ㅇ) buscam combinar explicações da contribuição das instituições à determinação de situações políticas com uma avaliação da contribuição de outros tipos de fatores, como as ideias, a esses mesmos processos (HALL; TAYLOR, 2003).

O Institucionalismo da Escolha Racional surge de um paradoxo: como existe uma estabilidade nas decisões do Congresso Norte-Americano, se, segundo os postulados da escola clássica sobre escolha racional, não deveria haver estabilidade para votação de leis no Congresso, pois as escalas de preferências legislativas e o caráter multidimensional das questões mudariam a cada ciclo, e assim invalidariam as preferências da maioria precedente? Explica que as instituições do Congresso diminuem os custos de transação ligados à conclusão de acordos, de modo a propiciar aos parlamentares os benefícios da troca, permitindo a adoção de leis estáveis.

Na prática, as instituições resolvem uma grande parte dos problemas de ação coletiva enfrentados pelos legisladores. Possui como referência os trabalhos de Oliver Williamson, que estuda os aspectos organizacionais de uma empresa e seu esforço para reduzir custos. Douglas North aplicou teses similares às questões das instituições políticas. Gary W. Cox e Mathew D. McCubbins deram ênfase ao modo como os partidos políticos estruturam as deliberações. John Ferejohn examina as relações entre o Congresso e os tribunais e como desenvolve-se a capacidade do Congresso de enquadrar as autoridades administrativas.

A partir dos anos 90 os teóricos desta escola buscaram explicar outros fenômenos políticos como o comportamento de coalizões segundo os países, o desenvolvimento histórico das instituições políticas e a intensidade de conflitos étnicos. Adam Przeworski, Barbara Geddes, Gary Marks analisam as transições para a democracia segundo o modelo da teoria dos jogos. George Tsebelis e outros estudam as consequências da reforma institucional no seio da União Europeia.

Os debates internos desta escola trazem alguns pontos comuns: 1ㅇ) empregam uma série de características de pressupostos comportamentais. Postulam que os atores compartilham um conjunto de preferências e se comportam de modo a buscar a máxima satisfação; $2^{\circ}$ ) consideram a vida política como uma série de dilemas de ação coletiva. Utilizam recursos como o "dilema dos prisioneiros" e a "tragédia dos bens comuns" para explicar o resultado ótimo de interações coletivas; 3) afirmam que as instituições estruturam as interações entre atores, na medida que o seu comportamento é determinado por cálculos estratégicos, e aquelas (as instituições) propiciam ganhos de troca, oferecendo informações e mecanismos que diminuem as incertezas; 4ㅇ) o processo de criação de instituições é geralmente centrado na noção de acordo voluntário entre os atores interessados.

O Institucionalismo Sociológico remonta os anos 70, quando alguns sociólogos começam a contestar a distinção tradicional entre a esfera do mundo social (burocrática) e as esferas associadas à cultura. Desde Max Weber, numerosos sociólogos consideraram as estruturas burocráticas que dominam o mundo moderno, sejam elas ministérios, empresas, escolas, grupos de interesse, etc., como produtos de um intenso esforço de elaboração de estruturas cada vez mais eficazes, destinadas a cumprir procedimentos e tarefas formais ligadas a essas organizações. 
Segundo os teóricos desta escola, essas formas e procedimentos deveriam ser considerados práticas culturais, comparáveis aos mitos e às cerimônias elaborados pelas sociedades. Buscam explicar por que as organizações adotam um específico conjunto de formas, procedimentos ou símbolos institucionais, com particular atenção à difusão dessas práticas. Frank Dobbin usa esse enfoque para mostrar como concepções culturalmente determinadas do Estado e do mercado condicionaram a política ferroviária na França e nos Estados Unidos no século 19. John W. Meyer e W. Richard Scott adotam o mesmo enfoque para explicar a proliferação de programas de formação nas empresas norte-americanas. Neil Fligstein serve-se dele para mostrar a diversificação da indústria norte-americana, e Yasemin Soyal o faz para explanar a atual política de imigração na Europa e na América do Norte.

As principais características desta escola são: 1의) definem instituições de maneira muito mais global que os pesquisadores em Ciência Política, incluindo não só regras, procedimentos ou normas formais, mas também os sistemas de símbolos, os esquemas cognitivos e os modelos morais que guiam a ação humana; 2) enfatizam a natureza interativa das relações entre as instituições e a ação individual, na qual cada polo constitui o outro.

Assim, para estabelecer uma linha de ação, o indivíduo utiliza os modelos institucionais disponíveis ao mesmo tempo que os confecciona. Sustentam que as organizações adotam uma nova prática institucional por razões que têm menos a ver com o aumento da sua eficiência (defendida pela Escola da Escolha Racional) do que com reforço que oferece a sua legitimidade social. John L. Campbell exprime bem esse modo de ver as coisas ao falar de uma "lógica das conveniências sociais" por oposição a uma "lógica instrumental" (HALL; TAYLOR, 2003, p. 207-211).

Para alguns estudiosos existe uma quarta corrente, o Institucionalismo Econômico, contudo os pressupostos da interação estratégica, direitos de propriedade e seleção competitiva, que fundamentam tal escola, já estão contidos na Escola da Escolha Racional.

Apesar das semelhanças e da interação entre elas, surgem estudos na área que ficaram conhecidos como a Nova Economia Institucional (NEI). Esta preocupa-se, fundamentalmente, com aspectos microeconômicos, com ênfase na teoria da firma, que mescla história econômica, economia dos direitos de propriedade, sistemas comparativos, economia do trabalho e organização industrial. As figuras mais expressivas desta escola são Ronald Coase, Oliver Williamson e Douglass North, que desenvolvem estudos na área de organização e operação das empresas, formação de mercados, a divisão de atividades entre corporações e mercados e a formação de sistemas de mercado e instituições que constituem esses sistemas. Centram sua análise nos custos de transação e, no caso de North, em estudos mais recentes, no papel do poder e ideologia na evolução institucional e sistêmica.

As várias abordagens da NEI se desenvolveram a partir de uma variedade de recortes analíticos específicos, que delimitam diferentes objetos a partir da eleição de um nível de análise determinado e da construção de um modelo teórico adequado a este. Os principais níveis de análise definidos por estas abordagens se referem a subsistemas da estrutura institucional de uma economia capitalista, que possuem relativa autonomia, o que justifica o seu estudo dentro de enfoques teóricos especializados (PONDÉ, 2007, p. 8).

De acordo com o exposto, e em virtude da dificuldade de um delineamento de todas as teorias aqui levantadas, será utilizada uma abordagem da teoria econômica institucionalista, a qual tem como pretenso objeto de estudo a evolução das instituições no capitalismo.

Assim, apesar de as Escolas Institucionalistas terem estruturado suas bases teóricas num período recente, as ideias e seus pressupostos podem ser emprestados para análise de períodos mais remotos, como a formação dos Estados.

\section{AS INSTITUIÇÕES E A FORMAÇÃO DO ESTADO BRASILEIRO}

A formação do Estado brasileiro está diretamente relacionada ao processo que culminou com a consolidação das relações de produção capitalistas e do modo de vida liberal. A construção desse sistema econômico passa por dimensões do colonialismo ao imperialismo e de conquista de territórios. Assim, a construção do Brasil está diretamente relacionada à invenção e conquista da América Latina, por meio do capitalismo colonial moderno e da Europa como centro do mundo (eurocentrismo), como um novo padrão de poder mundial. 
A construção do Estado brasileiro segue, portanto, o que ocorreu em toda a América Latina, na qual o capital buscou concretizar um eixo de articulação das formas historicamente conhecidas de controle e exploração do trabalho, com mecanismos de classificação e diferenciação de raças, com o objetivo de subjugar e dominar.

O descobrimento do Brasil insere-se num período conhecido como Idade Moderna (1453 - tomada de Constantinopla pelos turcos otomanos, indo até 1789 - início da Revolução Francesa). Esse período teve como principais características: i) foi um período de transição do feudalismo para o capitalismo; ii) fortalecimento das monarquias nacionais europeias; iii) prevalência de um regime político caracterizado, principalmente, pela centralização do poder nas mãos do monarca (rei); iv) período de descobrimentos marítimos feitos pelos europeus (principalmente Portugal e Espanha) e colonização e exploração das terras descobertas (especialmente na América e África); v) comércio marítimo como principal fator de desenvolvimento econômico das nações (mercantilismo); vi) fortalecimento da burguesia comercial europeia; vii) surgimento de movimentos de contestação ao poder da Igreja Católica (Reforma Religiosa) e formação de novas igrejas (Luterana, Calvinista e Anglicana); viii) desenvolvimento das artes plásticas e da cultura sob uma nova perspectiva (humanismo), principalmente com o Renascimento Cultural; ix) amplo desenvolvimento científico (Astronomia, Engenharia, Matemática, Anatomia, Biologia, etc.) no contexto do Renascimento Científico; $x$ ) acúmulo de riquezas na Europa, fruto da exploração das colônias na América; xi) início da Revolução Industrial no final da Idade Moderna; xii) contestação, principalmente com o lluminismo, do regime absolutista e crise deste sistema de governo no final da Idade Moderna (segunda metade do século 18) (VICENTINO; DORIGO, 2013, p. 79).

Baseado nos estudos, antes descritos, pode-se assinalar que no período do descobrimento do Brasil as dimensões institucionais que representavam este período, notadamente na Europa, eram: na economia ocorria o declínio do feudalismo e ascensão do capitalismo mercantil (grandes navegações e descoberta de novos continentes); na sociedade a ascensão da burguesia em detrimento da nobreza e do clero; na política a formação do Estado Moderno; na religião o surgimento da Reforma Protestante contra a hegemonia da unidade cristã; na cultura o movimento renascentista e como visão de mundo prevalecia o eurocentrismo.

O eurocentrismo tinha como principal característica a ideia de impor os interesses e a cultura europeia em todos os lugares. Este pensamento foi muito utilizado no período das Grandes Navegações e Descobrimentos Marítimos (séculos 15 e 16), principalmente portugueses e espanhóis, ao descobrirem novas terras na África, Ásia e América e introduzirem suas culturas (religião, língua, modos, costumes) entre os povos conquistados.

Para a compreensão sobre o Estado Moderno e os efeitos de tal instituição para o estabelecimento da estrutura jurídico-político-econômica da sociedade europeia e consequente processo de colonização na América Latina e no Brasil, deve-se buscar o entendimento de Max Weber em relação às formas de poder.

Inicialmente Weber destaca que a probabilidade de encontrar obediência a um determinado mandato pode fundar-se em diversos motivos, mas que, em bases de legitimidade, as formas totalmente puras de dominação são: a legal, a tradicional e a carismática (COHN, 1979, p. 128).

Nas relações dos quadros administrativos dominam a fidelidade pessoal do servidor, que é caracterizado por duas modalidades: 1) a estrutura puramente patriarcal de administração, quando os servidores são recrutados em completa dependência pessoal do senhor; 2 ) a estrutura estamental, em que os servidores são pessoas independentes (COHN, 1979, p. 131).

Esta última é uma característica do Estado Absolutista, em que não existem distinções entre os limites do público e os limites do privado. É baseado na autoridade patriarcal, que também pode se denominar patrimonial.

O patrimonialismo, portanto, explica a fundamentação do poder político, ou seja, como este se organiza e se legitima, e caracteriza-se pelo poder político organizado através do poder arbitrário/pessoal do príncipe e legitimado pela tradição. Tal legitimação pela tradição é ambivalente em relação à tendência dos dirigentes ao arbítrio pessoal. A tradição, ao mesmo tempo que a ampara, limita-a, ao reconhecer aos dominados certos direitos e imunidades sacralizados pelo tempo e costumes. É a coexistência dinâmica e tensa daquilo que a autora mexicana Gina Zabludovsky Kuper considera o cerne da estrutura patrimonial de poder: o binômio tradição/arbítrio. 
Se o arbítrio predomina, o patrimonialismo aproxima-se do que Weber classificou de patrimonialismo sultanista, ou patriarcal, ou puro. Se prevalece a tradição, o patrimonialismo tende a transformar-se em patrimonialismo estamental ou descentralizado, no qual as relações entre o príncipe e o corpo administrativo são mais estáveis e equalizadas (CAMPANTE, 2003, p. 156).

Segundo Neto (2008), o patrimonialismo é uma forma de exercício da dominação por uma autoridade, a qual está legitimada pela tradição, e tem como principal característica o poder individual do governante que, amparado pelo aparato administrativo recrutado com base em critérios unicamente pessoais, exerce o poder político sobre um determinado território.

Quando o príncipe organiza, em princípio, seu poder político, isto é, sua dominação não-doméstica, com o emprego da coação física contra os dominados, sobre territórios e pessoas extrapatrimoniais (os súditos políti$\cos$ ), da mesma forma que o exercício de seu poder doméstico, falamos de uma formação estatal-patrimonial. A maioria de todos os grandes impérios continentais apresentou, até os inícios da Época Moderna e ainda dentro desta época, um caráter fortemente patrimonial (WEBER, 1999, p. 240).

No Brasil, o processo de colonização importava este mesmo mecanismo de administração, do modelo patrimonialista.

Esta seria, portanto, uma das explicações para os problemas enfrentados pelo Brasil, ou seja, o caráter específico da formação histórica nacional, diante do passado colonial, na qual a estrutura administrativa de poder patrimonial do Estado português foi inteiramente importada para a Colônia e transformado em um padrão que, a partir dele, estruturaram-se todo o período colonial, a Independência, o Império e a República do Brasil.

A estrutura econômica no período colonial era dependente e baseada, nos quatro primeiros séculos, em cinco pilares básicos: 1) produção primária, 2) por meio da monocultura, 3) destinada à exportação, 4) realizada no latifúndio, 5) por mão de obra escrava ou assalariados mal-pagos. À margem ou com função complementar, as pequenas lavouras de subsistência formada por maioria de deserdados (BRUM, 1999).

A elite branca, proprietária de terras e de escravos, situava-se no topo da pirâmide social da Colônia. Os senhores de engenho, donos de imensa fortuna e dominando grande número de pessoas, formavam uma aristocracia de riqueza e poder, mas não uma nobreza hereditária do tipo que existia na Europa. O rei concedia títulos de nobreza por serviços prestados ou mediante pagamento. Eram os brancos ricos que exerciam o poder político na Colônia, monopolizando as decisões. Por exercerem seu controle sobre a massa da população colonial (negros e brancos pobres), os senhores tinham grande prestígio social (FAUSTO, 1995).

O poder político era concentrado nas mãos dos senhores de terras, com alguma participação dos comerciantes. No Império a vida política girou em torno dos dois grandes partidos políticos: o Conservador e o Liberal. Ambos representavam a classe senhorial.

A administração da Justiça, no Brasil, fazia-se por intermédio do Ouvidor-Geral, que ficava na Bahia, ao qual se poderia recorrer das decisões dos ouvidores das Comarcas, em cada Capitania, que cuidavam da solução das contendas jurídicas nas vilas. Tais funções judiciais eram confundidas com as funções administrativas e policiais, posto que os chanceleres, contadores e vereadores que compunham os Conselhos ou Câmaras Municipais desenvolviam as atividades jurisdicionais nas Comarcas durante o período colonial. As figuras dos corregedores, provedores, juízes ordinários, próprias da Justiça portuguesa, começaram a aparecer no Brasil, na medida em que a colonização foi se ampliando, exigindo uma estrutura burocrática e administrativa mais sofisticada (MARTINS FILHO, 1999).

O que se pôde perceber é que nesse período não existia um Estado brasileiro. A administração colonial portuguesa no Brasil buscou exercer de um lado o centralismo político, caracterizado por uma grande intervenção da metrópole, para um melhor controle da área colonial, e de outro a política local, marcada pela descentralização e que atendia aos interesses dos colonos, em virtude da autonomia dos poderes locais para com a metrópole. Os sistemas utilizados para exercer a administração foram os das Capitanias Hereditárias e depois dos Governos Gerais.

Esta estrutura colonial vai perdurar até a elaboração da primeira Constituição do Brasil em 1824, quando nasce o Estado brasileiro. Esta é a posição de muitos teóricos: só existe Estado quando existe uma Constituição. Esta é defesa feita por Hans Kelsen, pois, segundo este, antes do seu nascimento, somente teríamos o 
Estado de fato, uma vez que "nenhuma ordenação social - nem mesmo a chamada moral ou justiça - é considerada válida se não for, em certa medida, efetiva, ou seja, se o comportamento humano regulado por essa ordenação não se conformar a ela" (KELSEN, 1985, p. 64).

A influência dos preceitos liberais segue determinando as instituições em todas as Constituições brasileiras $(1824,1891,1934,1937,1946,1967,1988)$. De maneira geral têm forte conotação do liberalismo econômico, privilegiando o capital, o individualismo e a força do mercado; por outro lado, reduzindo o papel do Estado e desestimulando as lutas sociais e participação popular nos assuntos de gestão pública. ${ }^{5}$

A Constituição de 1988 instituiu o Estado Democrático de Direito destinado a assegurar o exercício dos direitos sociais e individuais, a liberdade, a segurança, o bem-estar, o desenvolvimento, a igualdade e a justiça como valores supremos de uma sociedade fraterna, pluralista e sem preconceitos, fundada na harmonia social. Estabelece ainda o fortalecimento da Federação, formada pela união indissolúvel dos Estados e Municípios e do Distrito Federal, declara seus princípios fundamentais e afirma a soberania popular, além de instituir como novo paradigma a democracia participativa.

Garantiu entre seus princípios fundamentais a redução das desigualdades, considerando a diversidade sexual, de raça, geração, e o combate a qualquer forma de discriminação. Além disso, primou pela garantia dos direitos humanos, dos direitos sociais e políticos. É, sem dúvida, um novo paradigma no arcabouço jurídico e democrático brasileiro.

A Constituição Federal, no caput do artigo 1ㅇ, garante que a República Federativa do Brasil constitui-se em um Estado Democrático de Direito e, no parágrafo único do artigo 1ํ, dispõe: Todo poder emana do povo, que o exerce por meio de representantes eleitos ou diretamente. Mais adiante, no inciso III do artigo 3, consagra que um dos objetivos fundamentais da República consiste em erradicar a pobreza e a marginalização e reduzir as desigualdades sociais e regionais (BRASIL, 1988).

Apesar de a Carta Magna de 1988 enumerar estes direitos e declarar o respeito aos direitos humanos, coletivos e individuais, o grande problema é a sua não efetividade, pois sua defesa depende sempre da institucionalização de um sistema de poder e de uma posição de poder na sociedade. Isto pode ser observado ao verificar que o objeto dos direitos econômicos e sociais são políticas públicas ou programas de ação governamental, que visam a suprimir carências sociais. De um lado os titulares desses direitos são os grupos carentes ou despossuídos - como sujeito coletivo ou individual - de outro o Estado, ou os particulares que detêm poder econômico e que estabelecem as diretrizes das políticas.

O Executivo não tem muito poder de manobra, executa o que está estabelecido nas leis. Apesar do revezamento de governos com tendências ideológicas para um Estado mais ou menos interventivo, o Brasil, a partir da redemocratização e da promulgação da Constituição de 1988 (que traz instrumentos da socialdemocracia, tais como a função social da propriedade, desenvolvimento social e mecanismos de participação popular) é um país capitalista, com todos os mecanismos do sistema neoliberal.

E o Judiciário garante que estas leis sejam cumpridas. E mesmo que se defenda a posição de um Judiciário mais atuante, e seja adepto da judicialização da política, esta função, de transformar a Constituição formal em Constituição substancial, vai estar adstrita ao contorno e aos limites constitucionais, ou seja, às leis que sofreram as influências dos valores e preceitos econômicas dominantes, além de provocar uma aporia do poder.

A atividade legiferante é desenvolvida por poucos, eleitos democraticamente, mas sem controle social (apesar dos mecanismos constitucionais). Assim, os legisladores estão sujeitos ao controle de quem tem mais força, o capital. O mesmo ocorre com a atividade judiciária, também desenvolvida por poucos, sem controle da sociedade, influenciada pelo capital e por correntes teóricas hegemônicas, baseados na racionalidade e que buscam afastar os diversos aspectos da Justiça, reduzindo todos os conflitos sociais ao mundo da racionalidade e da relação entre benefício e custo, como ocorre com as correntes teóricas da Análise Econômica do Direito e da Nova Economia Institucional.

\footnotetext{
${ }^{5}$ Deve-se guardar as proporções dos papéis dos agentes sociais e das instituições em cada período, respeitando as mudanças no papel do Estado como: Estado liberal, Estado social, Estado regulador.
} 
Nesse sentido, percebe-se que a estrutura social é baseada no capitalismo, avesso aos movimentos da sociedade. Nesta estrutura, quem tem mais força (o capital) influencia muito mais as instituições, que controlam o povo. Dessa forma, Executivo, Legislativo e Judiciário são muito mais passíveis de serem controlados do que controlar o povo. Se o povo acredita nesta estrutura, na sabedoria e capacidade dos notáveis e que o conflito entre as instituições é o melhor caminho para soluções das questões sociais, não existirão mais dúvidas sobre o justo e sobre a Justiça.

\section{CONCLUSÃO}

As instituições tais como o Judiciário, a sociedade, a política e a economia trazem no seu arcabouço teórico uma lógica determinada por construções de pensamento e correntes filosóficas e ideológicas que as sustentam. Por outro lado, o entendimento de seus efeitos e suas funções dentro de uma sociedade só se faz possível por meio do entrelaçamento de objetos de estudo e correspondentes escopos.

Assim, os resultados das inferências de tais instituições numa determinada sociedade devem trazer as diversas conexões possíveis com todas as outras dimensões que a sociedade produz.

Nesse contexto, e tomando-se como referência aquela ideia de estrutura trazida por Gramsci, é possível fazer uma descrição dos aspectos institucionais que caracterizam o Estado brasileiro atual, após a Constituição de 1988.

No Brasil, como se viu, a estrutura social está assentada em valores da racionalidade econômica. A autonomia da vontade privada e os pressupostos de liberdade e igualdade, anunciados pelo liberalismo e posteriormente pelo neoliberalismo, conduzem as relações sociais.

A Constituição mostra-se anacrônica em virtude do não cumprimento das promessas da modernidade e, atualmente, necessita de reformas exigidas para o atingimento de valores fundamentais como liberdade, igualdade e solidariedade, e ainda pela complexidade das novas sociedades e novos atores sociais.

No Brasil, o entendimento de Estado democrático é o mesmo que de democracia liberal representativa, e que traz um fenômeno cultural que norteia o pensamento coletivo, o chamado predomínio de notáveis, no qual as instituições devem ser fortalecidas, pois os agentes que lá se encontram, mediante voto ou concurso público, são os únicos capazes de resolver todas as questões sociais. Como é o caso do STF, no Brasil, como a última instância (depois deles, nem Deus... eles não erram, não têm vontade política, interesse pessoal ou de classe, etc.).

De acordo com o que se verificou com este estudo, pode-se propor o fortalecimento da soberania popular e de atividades públicas não estatais. O fortalecimento das instituições no Brasil, assim como a ampliação dos mecanismos democráticos, são elementos essenciais à construção de uma sociedade mais justa, contudo a efetividade dos preceitos constitucionais da Justiça e da equidade passa, necessariamente, por um aumento da participação direta da população na construção, exercício e controle das atividades públicas.

\section{REFERÊNCIAS}

BRASIL. Constituição Federal de 1988. Promulgada em 5 de outubro de 1988. Planalto, Brasília, 1988. Disponível em: <http:// www.planalto.gov.br/ccivil_03/constituicao/constituicaocompilado.htm>. Acesso em: 22 jan. 2017.

BRUM, Argemiro J. O desenvolvimento econômico brasileiro. ljuí: Ed. Unijuí, 1999.

CABRAL, Álvaro; NICK, Eva. Dicionário técnico de psicologia. 14. ed. São Paulo: Cultrix, 2006.

CAMPANTE, Rubens Goyatá. O patrimonialismo em Faoro e Weber e a sociologia brasileira. Dados, vol. 46, n. 1, p. 153-193, 2003. [on-line]. Disponível em: <http://dx.doi.org/10.1590/S0011-52582003000100005>. Acesso em: 12 set. 2016.

CARVALHO, Cristina A. P. de; VIEIRA, Marcelo M. F.; LOPES, Fernando Dias. Contribuições da perspectiva institucional para análise das organizações. Enanpad, Ribeirão Preto, 1999. Disponível em: <http://www.anpad.org.br/admin/pdf/enanpad1999-org-26.pdf>. Acesso em: 20 ago. 2016.

COHN, Gabriel (Org.). Max Weber: Sociologia. São Paulo: Ática, 1979. (Coleção grandes cientistas sociais).

CONCEIÇÃO, Octavio Augusto C. Os antigos, os novos e os neo-institucionalistas: há convergencia teórica no pensamento institucionalista? Análise Econômica, Porto Alegre: Faculdade de Ciências Econômicas, UFRGS, ano 18, v. 33, mar. 2000.

FAUSTO, Boris. História do Brasil. São Paulo: Ed. Universidade de São Paulo, 1995.

GIL, A. C. Como elaborar projetos de pesquisa. 4. ed. São Paulo: Atlas, 2007. 
HALL, Peter A.; TAYLOR, Rosemary C. R. As três versões do neo-institucionalismo. Lua Nova, São Paulo, n. 58, p. $194-201$, 2003. Disponível em: <http://www.scielo.br/pdf/In/n58/a10n58>. Acesso em: 20 jun. 2016.

HODGSON, Geoffrey M. The Approach of Institutional Economics. Journal of Economic Literature, v. 36, 1998.

IANNI, Octávio. A sociologia de Florestan Fernandes. Estudos Avançados, São Paulo, vol. 10, n. 26, p. 25-33, 1996. Disponível em: <http://dx.doi.org/10.1590/S0103-40141996000100006>. Acesso em: 10 ago. 2016.

KELSEN, Hans. Teoria Pura do Direito. São Paulo: Martins Fontes, 1985.

MARTINS FILHO, Ives Gandra da Silva. Evolução histórica da estrutura judiciária brasileira. Rev. TST, Brasília, vol. 65, n. 1, out./ dez. 1999.

NETO, Luiz H. R. A formação do Estado brasileiro: patrimonialismo, burocracia e corrupção. Revista de Mestrado em Direito da Universidade Católica de Brasília, v. 2, n. 1, 2008. Disponível em: <http://portalrevistas.ucb.br/index.php/rvmd/article/viewfile/2598/1589>. Acesso em: 16 jun. 2016.

PONDÉ, João Luiz. Nova economia institucional. FGV, São Paulo, 2007. Disponível em: <http://epge.fgv.br/we/Direito/NovaEconomialnstitucional/2008?action=AttachFile\&do=get\&target=nei1.pdf>. Acesso em: 30 ago. 2016.

SÁ, Vinicius Cláudio de. O desenvolvimento na perspectiva institucional: algumas reflexões sobre o processo de legitimação junto à sociedade. CIRCUITO DE DEBATES ACADÊMICOS, 1., 2011. Anais... Ipea, 2011. [on-line]. Disponível em: <http://www. ipea.gov.br/code2011/chamada2011/pdf/area5/area5-artigo18.pdf>. Acesso em: 22 jul. 2016.

SCOTT, Paulo Henrique Rocha. Direito Constitucional Econômico. Porto Alegre: Sergio Antonio Fabris Editor, 2000.

VASCONCELLOS, Marco Antonio Sandoval de. Manual de economia. 2. ed. 4ạ tiragem. São Paulo: Saraiva, 1996.

VICENTINO, Cláudio; DORIGO Gianpaolo. História geral e do Brasil. 2. ed. São Paulo: Scipione, 2013.

WEBER, Max. Economia e sociedade: fundamentos da sociologia compreensiva. Tradução Regis Barbosa e Karen Elsabe Barbosa. Revisão técnica Gabriel Cohn. Brasília, DF: Ed. Universidade de Brasília; São Paulo: Imprensa Oficial do Estado de São Paulo, 1999. 